\title{
The new 'opt-out' organ donation English law: Is the NHS ready for this?
}

\author{
Author: Thakshayene Mahenthran ${ }^{\mathrm{A}}$
}

In May 2020, the new 'opt-out' organ donation law was passed in England. This law is a crucial step to help battle the long waiting lists of patients awaiting a transplant. This article aims to explore some of the challenges that the transplant teams may face with the new law, as well as raising awareness among the junior doctors, especially with the new COVID-19 transplant guidelines. Successful transplantations require immense training of healthcare professionals, fast retrieval services, pre- and postoperative care of patients, intensive care management, life-long follow-up and management of patients. Organ transplant surgery is a life-changing moment for a patient. Ultimately, commissioning groups, clinicians and managers need to work together, evaluate the changes required and enact thorough business plans to ensure the NHS is not overwhelmed. Together with increasing the awareness of organ donation within the public, the government needs to support the NHS to fund, train and manage transplant centres to welcome this much-awaited 'opt-out' organ donation law in England successfully.

KEYWORDS: transplant, resources, NHS, opt out, organ donation

DOI: $10.7861 /$ clinmed.2020-0675

On 20 May 2020, in the midst of the global pandemic of COVID-19, the new 'Max and Kiera's law' was enacted in England. This law states that 'all adults in England will be considered as having agreed to donate their own organs when they die, unless they record a decision not to donate or are in one of the excluded groups. ${ }^{.1}$ Organ donation is potentially the most valuable gift that someone who is in critical need of it can receive. As of 11 September 2020 in the UK, there are 4,401 people waiting for an organ transplant. ${ }^{2} \mathrm{~A}$ systematic review carried out in 2019, comparing the consent rates of opt-out organ donation countries versus opt-in countries, showed that the opt-out consent increased the deceased donation rate by $21-76 \%$ over $5-14$ years, and deceased transplantation rate was increased by $38-83 \%$ over $11-13$ years. ${ }^{3}$ In December 2015 , Wales introduced their new 'opt-out' system, which has proved to be very successfully increasing donor consent rates to $80.5 \%$, in comparison with the rest of the UK at $66.2 \%{ }^{4}$

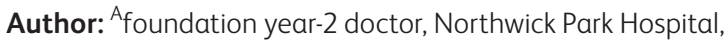
Harrow, UK
This new law is, unquestionably, a crucial step going forward in England with the increasing number of patients on the organ transplant waiting list. Along with increasing public awareness, the organ donation rates will start to increase very soon. However, is the NHS actually prepared for the potential increase in the number of organs?

For this law to be successful, each one of us need to play our role effectively. I will explore some of the challenges the transplant teams may face with the new law. I also hope this article helps to raise more awareness among junior doctors, especially with the new COVID-19 transplant guidelines.

Organ donation is something I feel strongly about. Being a regular blood donor and having signed up to the organ donation register since holding a driving licence, I feel it is absolute essential that every organ which has transplant potential should not be wasted. As a foundation doctor working in a district general hospital, organ donation is not a commonly heard conversation topic. These conversations, one may assume, are more commonly heard in intensive care settings, where patients are on the maximum level of treatment. It is a common misunderstanding that organs cannot be retrieved from dead patients. However, tissues such as the skin, tendons, bone and cornea, can be retrieved up to $24-48$ hours after death. ${ }^{5}$ While working in the emergency department, I had witnessed a patient being made palliative due to a major intracerebral haemorrhage. Unfortunately, as we were not able to get in contact with the family, we did not have the chance to donate any of the other valuable organs towards transplantation. However, now with the new law, it is essential that all doctors are aware of this and are trained for such a scenario.

Successful transplantation programmes consist of multiple factors: highly skilled medical professionals; good patient preparation and follow-up; fast retrieval services; adequate funding for theatres; and intensive care management.

A highly skilled procedure, such as this, requires in-depth specialist training, as well as a large number of healthcare professionals. From retrieval surgeons to transplant surgeons, anaesthetists, specialised transplant nurses, intensive care unit (ICU) nurses, therapists, specialised pharmacists etc, the list is endless. This team is made up of highly committed professionals, who dedicate their lives to working at any time of the day (ie whenever an organ is ready). It is currently a niche aspect of the NHS system, with only a few specialist transplant centres around the country. However, with the new 'opt-out' system, the number of surgeries will inevitably increase, resulting in the need for a 
larger workforce and the initiation of advanced training. As a foundation doctor, I feel there needs to be more exposure to transplant jobs early on to see what this career entails, and to potentially apply for training in such a pathway.

The efficient retrieval system works well in successfully recovering the deceased's organ and bringing it in a timely manner for the transplant operation to take place. I have been fortunate as a foundation doctor to have experienced a very delicate conversation with a patient's family. I was intrigued by the multidisciplinary approach within the intensive care team in supporting the patient, but also the struggles of organising an ICU bed within a busy district general hospital while the retrieval team arrived. With the increase in available organs, there will need to be multiple retrieval teams on standby to carry out more than one transplant surgery simultaneously. The local hospitals, in particular the ICUs, will see an increase in workload and an increase in intensive care bed pressures.

Last year, over 400 people died in England while being on the waiting list for an organ. ${ }^{6}$ This supports the importance of the 'opt-out' system and the need for this to be successful. However, patient preparation and follow-up requires a lot of input. Transplant patients are immunocompromised, and will need to be on life-long immunosuppressant therapy. This increases their risk of being more prone to diseases, infections and even cancers. Although organ transplantation will inevitably reduce the longterm burden that chronic failing organs place on the NHS, there will undoubtedly be additional pressures on the current existing healthcare system in the form of monitoring and follow-up appointments for post-transplant care in the immediate future. The British Transplantation Society have stated that, as of 2018 , over 50,000 patients are currently on the post-transplant follow-up list; this number is due to increase with a prediction of $20-25 \%$ more transplants over the next 5 years. ${ }^{7}$ This should be visualised by clinical commissioning groups and local stake holders, and be supported with extra funding.

Transplant centres currently have dedicated wards for preand post-surgical patients, requiring immediate intensive care management. During most winters in the UK, the NHS battles with lack of bed availability, leading to a lot of routine surgeries being cancelled. At times, this can put pressure on the transplant centres, especially if the number of organs are due to increase.

During the peak of the initial COVID-19 pandemic, almost all organ transplantation from living donors were stopped. A few high priority cardio-thoracic, liver and islet transplants occurred, however, overall transplant rates in the UK fell by over $80 \% .{ }^{8}$ Unfortunately, the unforeseen consequences of the pandemic has resulted in many valuable organs being wasted, not helping with the growing waiting list numbers. As the country fears for a second COVID-19 peak, the Organ and Tissue Donation and Transplantation Directorate (OTDT) UK have come up with a second surge plan to maximise the number of organs for transplantation. ${ }^{8}$ Successful transplantations have occurred in Singapore during the pandemic, using a tiered approach, riskstratifying the suitable candidates and donors. ${ }^{9}$ It is essential that all hospitals, especially the district general hospitals, are aware of the guidance to ensure no valuable organ is lost.

As is evident, in order for the new 'opt out' organ donation law to run successfully, there are many logistical challenges which will need to be addressed. Ultimately, there will need to be increased funding and investment into the current infrastructure. Increasing the number of transplant surgeries will eventually save costs from chronic condition management. This locally saved money should be channelled towards the transplant centres, where it can be used efficiently for the increasing demand. Commissioning groups, clinicians and managers need to carefully work together, evaluate the changes in services required and enact thorough business plans to ensure a successful transplantation.

Organ transplant surgery is a life-changing moment for a patient. The new opt-out law will undoubtedly put an increased demand on the transplant services in the UK. In order to successfully carry out organ transplantation while respecting the deceased's organ as well as ensuring the best outcome to the recipient, there needs to be increased funding to this service. The true impact of the new law in the past 3 months has not quite been felt yet, due to the combination of being a new law, as well as the COVID-19 pandemic causing reduced rates of transplantations. Together with increasing the awareness of organ donation within the public as well as junior doctors, the government needs to support the NHS to fund, train and manage transplant centres to welcome this muchawaited 'opt out' organ donation law in England successfully.

\section{Acknowledgements}

Thanks to Dr Aravinth Sivagnanaratnam for his suggestions contributing towards this manuscript.

\section{References}

1 NHS Blood and Transplant. Date announced for Max and Keira's Law to come into effect. NHS, 2020. www.organdonation.nhs.uk/ get-involved/news/date-announced-for-max-and-keira-s-law-tocome-into-effect [Accessed 13 September 2020].

2 NHS Blood and Transplant. Statistics about organ donation: Current UK statistics for organ donations and transplants. NHS, 2020. www.organdonation.nhs.uk/helping-you-to-decide/ about-organ-donation/statistics-about-organ-donation [Accessed 13 September 2020].

3 Ahmad MU, Hanna A, Mohamed AZ et al. A systematic review of opt-out versus opt-in consent on deceased organ donation and transplantation (2006-2016). World J Surg 2019;43:3161-71.

4 Welsh Government. Organ donation consent rates in Wales highest in the UK. Welsh Government, 2018. https://gov.wales/ organ-donation-consent-rates-wales-highest-uk-0 [Accessed 13 September 2020].

5 NHS Blood and Transplant. Tissue donation after death. NHS, 2020. www.nhsbt.nhs.uk/what-we-do/transplantation-services/ tissue-and-eye-services/tissue-donation/become-a-donor/tissuedonation-after-death [Accessed 13 September 2020].

6 NHS Blood and Transplant. Organ donation and transplantation: Give the gift of life after your death. NHS, 2020. www.nhsbt.nhs. uk/what-we-do/transplantation-services/organ-donation-andtransplantation [Accessed 13 September 2020].

7 British Transplantation Society. Transplant Sustainability and Resilience Summit - summary report. BTS. https://bts.org.uk/wpcontent/uploads/2018/09/Summary-of-Sustainability-summit.pdf [Accessed 13 September 2020].

8 NHS Blood and Transplant. COVID-19 second surge planning. NHS, 2020. https://nhsbtdbe.blob.core.windows.net/umbraco-assetscorp/19464/pol301.pdf [Accessed 13 September 2020].

9 Chung SJ, Tan EK, Kee T et al. Practical considerations for solid organ transplantation during the covid-19 global outbreak: the experience from Singapore. Transplant Direct 2020;6:e554.

Address for correspondence: Dr Thakshayene Mahenthran, Northwick Park Hospital, Watford Road, Harrow HA1 3U], UK. Email: thakshayene.mahenthran@nhs.net 